\title{
Exploring Factors Influencing Recruitment and Retention of Nurses in Lagos State, Nigeria within Year 2008 and 2012
}

\author{
Modupe 0. Oyetunde ${ }^{1}$, Olabisi 0. Ayeni2 ${ }^{2}$ \\ ${ }^{1}$ Department of Nursing, College of Medicine, University of Ibadan, Ibadan, Nigeria \\ ${ }^{2}$ Lagos State School of Nursing, Lagos, Nigeria \\ Email: ${ }^{*}$ modupeoyetunde@gmail.com, ${ }^{*}$ mooyetunde@comui.edu.ng, olabisiayeni@yahoo.com
}

Received 27 May 2014; revised 25 June 2014; accepted 16 July 2014

Copyright (C) 2014 by authors and Scientific Research Publishing Inc.

This work is licensed under the Creative Commons Attribution International License (CC BY). http://creativecommons.org/licenses/by/4.0/

\section{Abstract}

Objective: To explore the factors influencing recruitment and retention of nurses in Lagos State Hospitals. Background: Despite the perceived efforts made by Hospitals Management in Lagos State to recruit and retain nurses, there is still inadequate number of nurses to match the demand of care needed by patients in the hospitals. Methods: The descriptive study utilized mixed methods to gather data. It consisted of 330 consented and randomly selected nurses for the survey and 14 purposively selected nurse leaders and Director for the interview. The instruments were pretested questionnaire, semi-structured interview guide and existing records. Result: The study revealed that all health institutions in Lagos State were aware of the standard procedures of recruitment of nurses, but often engages in replacement rather than proper recruitment. Most of the Nursing leadership positions in Lagos State were vacant. More than half $(68.2 \%)$ of the nurse respondents were not sure if they would still be working in their health institution in the next five years. It was revealed that the turnover rate of nurses in the State Health institutions was higher than the Federal health institutions in Nigeria. Conclusion: Increment in salary and allowances rated the best influence on recruitment and retention of nurses in Lagos State. Lack of nursing leadership; sense of job security and work environment were the major factors influencing recruitment and retention of nurses. There is need for adequate human resource planning; increased efforts and formulation of policies that will improve recruitment and retention of nurses in Lagos State of Nigeria.

\section{Keywords}

Recruitment of Nurses, Retention of Nurses, Shortage of Nurses, Nursing Leadership, Nigeria

\footnotetext{
${ }^{*}$ Corresponding author.
} 


\section{Introduction}

Health care systems globally have experienced shifts in population demographics, pattern of diseases, consumer expectations, cost of health care and most importantly the shift in the principles that organize the delivery of health care services. Great advances have also been recorded in medicine and health technologies in form of growing number of effective and affordable interventions. Despite these accelerating advances, several low-income countries such as Nigeria have experienced a decline in their health outcomes [1].

A major challenge in health care is the shortages in the healthcare workforce. Human resource crisis has shown to be a key factor influencing health outcomes [2] and countries with the worst shortages of Health Human Resource (HHR) are also the ones with the worst health indicators and highest infant and child mortality [3].

The main factors driving the human resource problem have been identified in Nigeria as insufficiently resourced and neglected health systems; Poor human resources planning and management practices and structures; unsatisfactory working among others [4]-[7].

Nurses are described as veritable caregivers and the strength of every health system [8]. Nursing represents the largest group of health professionals [9] and has been experiencing persistent shortage. Since 2002, nursing shortage has been termed a global crisis where supply of nurses cannot meet the demand.

While the WHO recommends a nurse to a population ratio of 700, English-speaking Caribbean nations currently have 1.25 nurses for every 1000 people and around 3 in every 10 nursing positions remain unfilled. Zambia had nurse population ratio of 1 to 1500. In Malawi, there are only 17 nurses for every 100,000 people. Nigeria currently has 148,129 nurses to cater for its population of above 150 million [10], with nurse population ratio of 1 to 1012 people.

Evidence suggests that shortage of nurses is detrimental not only to quality of patient care, but also to staff morale, which in turn affects staff retention [11]. Patients' mortality rates are higher where standards are weaker, nurse turn over and understaffing is persistent [12]. High patient-to-nurse ratios have been shown to lead to frustration and job burnout, which is linked to higher turnover [13]. Significant relationships among workplace incivility, stress, burnout, turnover intentions, total years of nursing experience, and RN education levels have also been reported in studies [14].

In the bid to find solution to the crisis of nursing shortage, the International Council of Nurses (ICN) initiated five priority areas, among which is retention and recruitment of nursing personnel [15]. Recruitment and retention are two human resources functions that require strategic thought and planning if effectual and effective outcomes are expected. Successful recruitment begins with proper employment planning and forecasting. Recruitment of Registered Nurses by a facility and then the retention of those nurses are major worldwide concern in today's nursing shortage environment and also for health policy-makers [16]. Data from both developed and developing countries tend to indicate that nursing recruitment and retention are serious issues and organizations are having difficulty recruiting new nurses and retaining current staff [17].

Many factors influence intention to stay once employed. These factors are either systemic or personal in nature. Systemic factors are constraints in hospital budget, remuneration, practice autonomy, work load, flexible shift, and opportunities for career advancement. Age of nursing work force, decline in the number of nurses graduating from the school of nursing and many inexhaustible factors determine availability of nurses for employment [18]-[21]. Vacancy positions and turnover rates are indicators of problems in recruitment and retention of nurses. Vacancies are reported in many countries, including developing countries such as South Africa, where an average of $40.3 \%$ of professional nurses' posts were vacant in 2008 [22]. Job turnover rate is also high in most countries. In countries such as the United Kingdom (UK) and the United States of America (USA), turnover rates are quite significant, as they are estimated to be around $20 \%$. The performance and quality of a health care delivery system ultimately depend on the quality of the number, the turnover rates and motivation of the health human resources [23]. Several studies have demonstrated nurses’ dissatisfaction, burnout, stress, and motivation in both developed and developing countries, however, not much has been done in Nigeria on the subject of factors influencing recruitment and retention of nurses as perceived by nurses (employees) and the nurse managers (employers), hence, the need for this study.

\section{Research questions:}

1) What are the strategies used for recruitment of nurses?

2) What are the strategies used for retaining nurses? 


\section{Materials and Methods}

This descriptive was carried out in Lagos State, Nigeria. It involved nurses from all categories of health care facilities (Tertiary, Secondary, Primary and Private) in the State. Lagos State, just like any other State in Nigeria does not practice skill mix. Employment of nurses is contingent upon acquisition of Registered Nurse and Registered Midwife licensure. Where a nurse is employed with RN only, such is expected to have additional qualification in any of the nursing specialty areas at the nearest possible time. A full practicing nurse in Nigeria is one with RN plus any other qualification in nursing specialty, which means possession of dual certificates. Although Lagos is the smallest State in Nigeria, it has a population of about 21 million, the highest urban population which is over $5 \%$ of the national estimate [24].

The study employed a mixed method approach to identify factors influencing recruitment and retention of nurses in Lagos State.

Sampling procedure: A two stage sampling procedure was done, first, the setting and then the participants. Purposive sampling technique was used to select the health institutions based on their types and number of nurses working in such facilities. These facilities were Lagos University Teaching Hospital (LUTH); General Hospital Lagos (secondary health institution); Alimosho Primary Health Centre (primary health institution) and Saint Nicholas Hospital (Private hospital). Lagos University Teaching Hospital had 683 nurses. General Hospital Lagos had 226 nurses. Alimosho Primary Health Care centre had 42 nurses and Saint Nicholas Private Hospital had 72 nurses. In all, there were 1023 nurses in all the settings.

In each setting, one in every three (1:3) eligible nurses was selected to participate in the survey, where such declined, the researchers moved to the next nurse. The Nurse Managers and Directors were purposively selected to participate in the interview.

Method of data collection: At each setting, after sampling and consent had been obtained, questionnaire was distributed to nurses. Three hundred and forty (340) copies of questionnaire were distributed in all. Fourteen (14) in-depth interviews were carried out among Nurse Managers and Directors. Data from existing records were also reviewed to answer the research questions.

Instruments: The instrument was developed after a thorough literature review. Section A of the structured interview guide consisted questions on socio-demographic data of respondents. Section B1 gathered data on recruitment strategies, staffing status and related influencing factors. Section B2 sought information on the retention strategies and related factors. Secondly, a self-administered questionnaire of 60 items divided into four sections was used for the survey. Section A of the questionnaire included the socio-demographic data. Section B1gathered data on nurses' perception on staffing status. Section B2 gathered data on nurses' perception on the recruitment strategies/policies used by employers. Section B3 gathered data on nurses’ perception of factors influencing employers' recruitment in Lagos State. Section B4 sought information on the factors that influences nurses' acceptance of employment. Section B5 gathered data on nurses’ perception on factors influencing retention. The instrument was pre tested among 16 nurses in Oyo-State. The nurses shared similar characteristics with the nurses under study. The Cronsbach's Alpha score was $\mathrm{r}=0.81$.

Information about the number of nurses from 2008 to 2012 was obtained from the hospitals documents for calculation of turnover rate in each health institution. A letter was written to the Nursing and Midwifery Council of Nigeria to gather records of the number of nurses who graduated from Schools of Nursing in Lagos State from 2008 to 2012.

Ethical consideration: Participation was voluntary and participants were allowed to withdrawal at any stage. Confidentiality of person and information were assured and there was no harm done to individuals or organizations. Ethical approval was obtained in May, 2013 from the Lagos University Teaching Hospital Health Research and Ethics Committee. The nurse administrators and Directors in charge of recruitment of nurses were duly informed and they consented to be interviewed and also provided access to the nurses. The nurses were provided with information about the study and they gave consent to participate.

Statistical analysis: Statistical Package for Social Science software version 17 [25] was utilized to analyze the questionnaires. Bivariate analyses compared demographic characteristics such as age, gender, professional qualification, and years of experience. Chi square was used to compare categorical variables and Anova for continuous variables.

For structured interview, notes and audiotape recorder were used during the interview, and data analyzed according to the steps proposed by Marshall and Rossman [26]. Other emerged themes different from the struc- 
tured interview were organized and prepared data for analysis, reading and rereading through data to obtain a general sense of the information and its overall meaning.

\section{Results}

A total of 330 (97\%) fully completed questionnaire was retrieved from the participants out of 340 distributed.

Socio-Demographic Characteristics: Table 1, Figure 1 and Figure 2 summarize the characteristics of the respondents.

As shown on Table 1, out of the 330 participants, 93\% were females and $77.9 \%$ were married. Most of the respondents (80.0\%) were Christians, 63.3\% of the respondents are Yoruba, others hailed from Igbo, Hausa, Fulani and middle belt. $45.5 \%$ were between ages 41 - 50 years, while $26.7 \%$ were aged between 31 - 40 years. The minimum age was 20 and the maximum was 59 years. The mean age was $40.9 \pm 6.4$ years.

As shown in Figure 1, 27.9\% of respondents are Chief Nursing Officers/Chief Matrons, Senior Nursing Officers/sisters (20.3\%); Principal Nursing officers/matrons (20.3\%); Assistant Chief Nursing Officers/senior matrons (14.5\%) and Nursing officers/sisters (17\%).

About 38.8\% of the respondents had RN and RMas shown in Figure 2. 25.8\% had BSc or BNSc; $18 \%$ had only RN; $17 \%$ had MSc. Respondents' years of experience were: $34.5 \%$ for 11 - 15 years; $23.9 \%$ for 16 - 20 years, below 5 years $7.9 \%$ while those with 20 years and above were $12.7 \%$.

Table 1. Socio-demographic characteristics of respondents.

\begin{tabular}{|c|c|c|}
\hline Variables & Frequency & Percentage (\%) \\
\hline \multicolumn{3}{|l|}{ Age (yrs) } \\
\hline $20-30$ & 28 & 8.5 \\
\hline $31-40$ & 88 & 26.7 \\
\hline $41-50$ & 150 & 45.5 \\
\hline $51-60$ & 64 & 19.4 \\
\hline Total & 330 & 100.0 \\
\hline \multicolumn{3}{|l|}{ Gender } \\
\hline Male & 22 & 6.7 \\
\hline Female & 308 & 93.3 \\
\hline \multicolumn{3}{|c|}{ Marital Status } \\
\hline Single & 68 & 20.6 \\
\hline Married & 257 & 77.9 \\
\hline Separated & 1 & .3 \\
\hline Divorced & 3 & .9 \\
\hline Widowed & 1 & .3 \\
\hline \multicolumn{3}{|l|}{ Religion } \\
\hline Christianity & 264 & 80.0 \\
\hline Islam & 61 & 18.5 \\
\hline Others & 5 & 1.5 \\
\hline Total & 300 & 100.0 \\
\hline
\end{tabular}




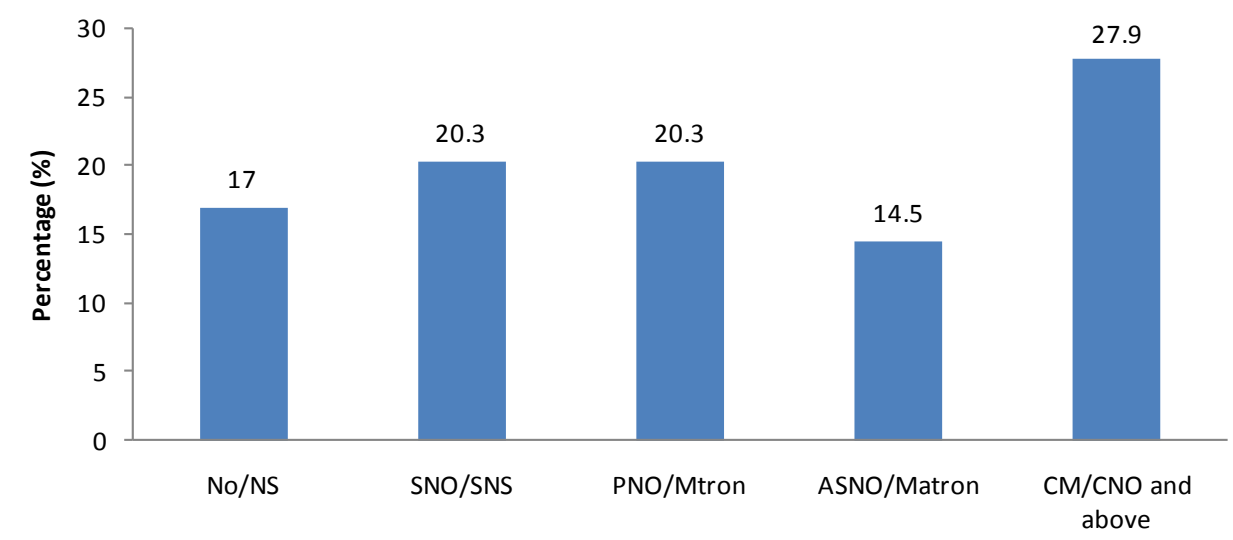

Figure 1. Designation of nurses under study. NO/NS are Nursing officers or nursing sisters on Grade Level 08, the entry level for fresh graduate or diplomat nurses. SNO/SNS are Senior Nursing Officers/Sisters in Grade Level 09, PNO/Matron are Principal Nursing Officers/Matron in Grade Level 10 or 12, ACNO are Assistant Chief Nursing officers/Senior Matrons on Grade Level 13, CM/CNO are the Chief Nursing or Chief Matrons on Grade Level 14.

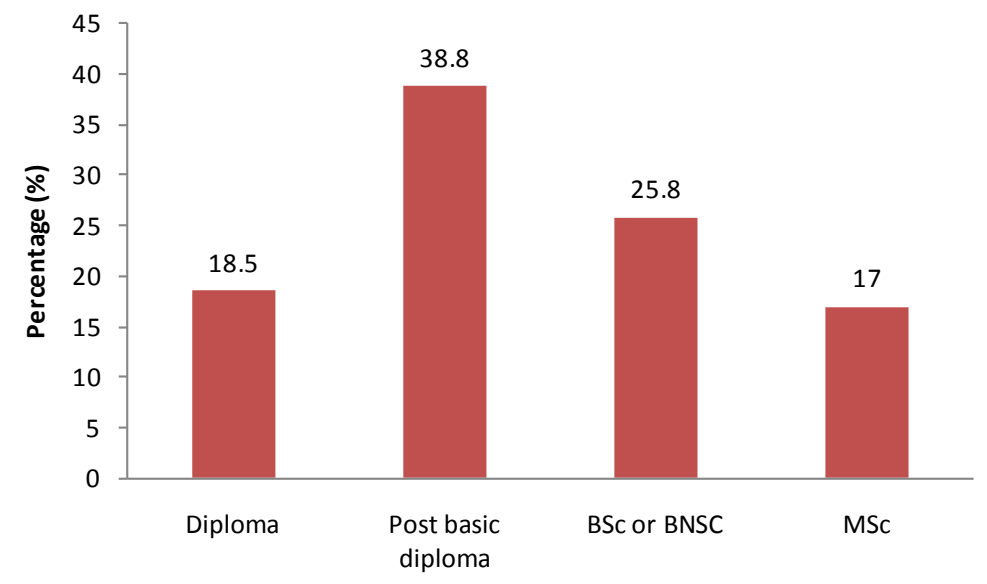

Figure 2. Highest qualification of respondents. Diploma represent nurses who have single basic qualification i.e. RN only. Post basic diploma represent nurses who have dual qualification i.e. RN and another specialization. BSc/BNScrepresent the graduate nurses while MSc represent nurses with masters degree.

Perception on Staffing Status: About 114 respondents (34.5\%) perceived the nurse: patient ratio on their ward to be between 1:6 - 1:10, while 108 (32.7\%) perceived their nurse: patient ratio to be between 1:11 - 1:15 and also $32.7 \%$ believed they work with nurse patient ratio of 1:2 - 1:5. Majority of respondents (77.9\%) posited there are not enough nurses to get work done in their hospitals and 153 (46.4\%) of respondents stated they have once committed an omission in while on duty.

Factors influencing employers' recruitment (Nurses perception): Findings revealed that majority of respondents $82(24.8 \%)$ strongly agreed that hospital budget and leadership of the health organization influences recruitment of nurses. The respondents (33.3\%) strongly disagreed that their employers made deliberate efforts to improve recruitment by engaging the strategy of competitive salary structure, About 94 (28.5\%) agreed that Hospital's reputation influences their acceptance of employment, while 97 (29.4 \%) strongly agreed that Salary influences their acceptance of employment. The respondents (35.2\%) disagreed that location of health institution influences their acceptance of employment. The respondents (28.5\%) agreed that sense of job security influences their acceptance of employment, while 75 (22.7\%) strongly agreed.

Nurses' perception on factors influencing retention: the respondents (28.8\%) disagreed and (25.5\%) strongly disagreed that their employers made deliberate effort to improve retention of nurses by organizing and 
funding continuing education. The respondents (33\%) disagreed that their employers made deliberate effort to improve retention of nurses by ensuring re-imbursement for their conference fees.

Factor that best influence retention of Nurses: From Table 2, about 82 respondents out of 330 identified increment in salary and allowances as the best factor that could retain them in their hospitals; 73 identified job security; 53 stated opportunities for career development; 28 identified working environment, and 22 posited opportunities to attend sponsored seminars and conferences as the best factor that can influence their retention.

Structured Interview: there were 14 nurse managers and directors involved in the recruitment and retention of nurses. They were available and consented to be interviewed.

Characteristics: Out of the 14 interviewed, six occupied the position of Assistant Director of Nursing of this number, 5 were in acting capacity, 2 were Chief Matron/Apex Chief Nursing Officers, 1 Permanent Secretary, 1 Chairman and 4 Directors of Administration. Eight have General Nursing and Midwifery and other diploma courses as their highest professional qualification, 4 have Master degrees in Public Health and Public Administration, while 2 have Bachelor in Nursing Science degree.

In Figure 3 majority (68.2\%) of the respondents were not sure if they will still be working in their health institution in the next five years. $23.6 \%$ responded in the affirmative while $8.2 \%$ responded they will not be working in their hospitals in the next 5 years.

Recruitment Strategies: All the respondents interviewed confirmed that the process of recruitment involved: submission of application by candidates; screening of application and short listing eligible candidates for examination and subsequent interview. Successful candidates will be recommended for approval and issuance of

Table 2. Factor that best influence retention of nurses.

\begin{tabular}{|c|c|c|}
\hline Perceived factors influencing recruitment & Frequency & Percentage \\
\hline Job security & 73 & 22 \\
\hline Increment in salary and allowances & 82 & 24.8 \\
\hline Provision of opportunities for career development & 53 & 16.1 \\
\hline Provision of good work environment & 28 & 8.5 \\
\hline Flexible Shifting style & 8 & 2.42 \\
\hline Promotion every three years & 10 & 3 \\
\hline Prevention of violence by patients and relatives & 1 & 0.3 \\
\hline Provision of adequate equipment & 4 & 1.2 \\
\hline Posting to hospital near home and child care facilities & 5 & 1.5 \\
\hline Adequate staffing to reduce workload & 8 & 2.42 \\
\hline Work autonomy & 11 & 3.33 \\
\hline Opportunities to attend sponsored seminars and conferences/training & 22 & 6.7 \\
\hline Good leadership/Mentoring & 4 & 1.2 \\
\hline Provision of nurse assistant/aides & 2 & 0.6 \\
\hline Cancellation of ad-hoc jobs nurses do & 3 & 0.9 \\
\hline Subsidy on medical expenses & 2 & 0.6 \\
\hline Love and dedication to Nursing & 14 & 4.24 \\
\hline
\end{tabular}

82 respondents out of 330 identified increment in salary and allowances as the best factor that can retain them in their hospitals, 73 identified job security, 53 stated opportunities for career development, 28 identified good working environment, and 22 posited opportunities to attend sponsored seminars and conferences as the best factor that can influence their retention. 14 identified love and dedication to Nursing profession, 10 posited promotion every three years, 8 identified flexible work schedule and adequate staffing to reduce workload, 5 posited posting to hospitals near home and child care facilities,4 posited provision of adequate equipment and good leadership, 2 identified provision of nursing aides and subsidy in medical expenses. 


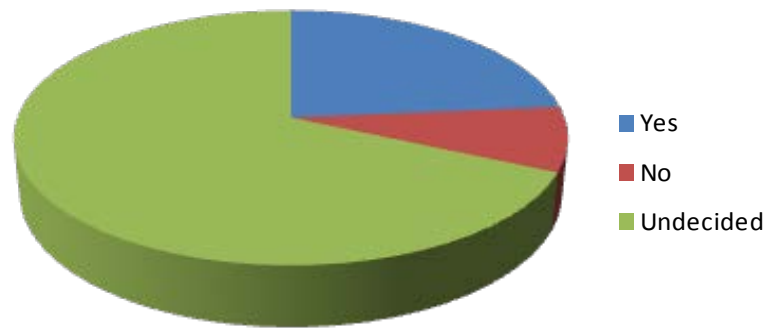

Figure 3. View of respondents on working in their hospitals in the next 5 years.

offer of appointment letter. Letter of acceptance of offer and assumption of duty by candidates will then follow. Eight respondents stated identification of vacant positions as a strategy for recruitment. All the health institutions did not advertise or give awareness either electronically or in print as a strategy for recruitment. About 71.4\% organized orientation/induction after recruitment. All respondents employed both internal and external sources of recruitment.

Staffing Plan: All heath institutions utilize combination of strategies to plan staffing except the use of World Health Organization Nurse-Patient Ratio. Patient's acuity, targeting difficult areas for supply, bed occupancy rate/number of beds are strategies utilized in staffing wards in Lagos State hospitals.

Retention Strategies: Strategies employed by health institutions in Lagos States includes; Provision of training and growth opportunities, providing study leave for training, sponsoring nurses for Conferences and Workshops, improving and maintaining safety of nurse, providing assistance to nurses who work alone, ensuring open and timely communication and open door policies, ensuring availability of work resources, minimizing work related injury by providing lifting equipment, and provision of car loan, house loan, transportation allowance and vacation in form of annual leave. Other strategies are ensuring annual promotion for eligible nurses, and increment in salary and allowances. About $57.1 \%$ agreed that nurses do not participate in decision making regarding their patients and profession.

Recruitment and Retention policies: Recruitment and retention policies employed by hospitals in Lagos State do not include Nurse: Patient ratio and only $28.6 \%$ engage in regular personal budgeting. These policies were being discussed in the management meetings.

Workload: About $42.9 \%$ described nurses workload as heavy, $35.7 \%$ described it as normal while $21.4 \%$ described it as minimal.

Turnover Rate Calculation of Health Institutions in Lagos State from 2008 to 2012.

As shown in Table 3, turnover rates of nurses in the state health institution in 2008 were $7.2 \%$, and data not available in other health institutions. In 2009, the turnover rates of nurses in the federal health institution were 1.9\%, and 6.3\% in State Health Institution. In 2010 federal health institution had nurse retention rate of 1.9\% while State had 3.8\%. In 2011 federal health institution had nurse retention rate of 2.2\% while State had 4.8\%. In 2012 federal health institution had nurse retention rate of 1.7\% while State had 3.3\%.

Also as shown on Table 4, all health institutions in Lagos State experienced $100 \%$ vacant positions in positions of the Director of Nursing Services (Grade Level 17), Deputy Director of Nursing Services (GL 16) and Assistant Director of Nursing Services (GL 15) since 2008 except 2008 and 2012 when reduction to 66.7\% was observed in State hospitals. Records were not available in private hospital.

Association between demographic variables and recruitment: Age of nurses $(p<0.05)$, duration of qualification as a nurse $(p<0.05)$, have significant influence on recruitment. Gender $(p>0.05)$ does not have significant influence on recruitment.

Association between demographic variables and retention: Age of nurses $(p<0.05)$, duration of qualification ( $p<0.05)$ and current designation $(p<0.05)$ were significantly associated with retention. However, Gender $(p>0.05)$ and professional qualification of nurses $(p>0.05)$ does not have significant influence on retention.

Testing the Influence of hospital's reputation, monetary incentives, work autonomy and Recruitment using Anova $\alpha=0.05$.

There is a statistically significant relationship between Work Autonomy, Hospital's Reputation, Monetary Incentives and recruitment $(\mathrm{p}<0.05)$.

From Table 4, Hospital's Reputation and Monetary Incentives positively influenced retention $(\mathrm{p}<0.05)$ ex- 
Table 3. Turnover rate calculation of health institutions in Lagos State from 2008 to 2012.

\begin{tabular}{|c|c|c|c|c|c|c|}
\hline \multicolumn{2}{|c|}{ Year/institution } & \multirow{2}{*}{$\begin{array}{c}\text { Number of exit } \\
-\end{array}$} & \multirow{2}{*}{$\begin{array}{l}\text { Number of } \\
\text { personnel at the } \\
\text { beginning of } \\
\text { period } \\
-\end{array}$} & \multirow{2}{*}{$\begin{array}{l}\text { Number of } \\
\text { personnel at the } \\
\text { end of period }\end{array}$} & \multirow{2}{*}{$\begin{array}{l}\text { Calculation of turnover rate (no } \\
\text { of exit } \div \text { by average no of Nurse } \\
\text { at the period } \times 100\end{array}$} & \multirow{2}{*}{$\begin{array}{c}\text { Turnover rates (\%) } \\
\text { - }\end{array}$} \\
\hline 2008 & Federal & & & & & \\
\hline & State & 135 & 1945 & 1810 & $135 \div 1877.5 \times 100$ & 7.2 \\
\hline & Local & - & - & & - & - \\
\hline & Private & - & - & & - & - \\
\hline \multirow[t]{4}{*}{2009} & Federal & 12 & 656 & 644 & $12 \div 650 \times 100$ & 1.9 \\
\hline & State & 129 & 2115 & 1989 & $129 \div 2052 \times 100$ & 6.3 \\
\hline & Local & - & - & & - & - \\
\hline & Private & - & - & & - & - \\
\hline \multirow[t]{4}{*}{2010} & Federal & 13 & 669 & 695 & $13 \div 682 \times 100$ & 1.9 \\
\hline & State & 81 & 2155 & 2074 & $81 \div 2114.5 \times 100$ & 3.8 \\
\hline & Local & - & - & & - & - \\
\hline & Private & - & - & & - & - \\
\hline \multirow[t]{4}{*}{2011} & Federal & 15 & 696 & 681 & $15 \div 688.5 \times 100$ & 2.2 \\
\hline & State & 104 & 2205 & 2098 & $104 \div 2151.5 \times 100$ & 4.8 \\
\hline & Local & & - & & - & - \\
\hline & Private & - & & & - & - \\
\hline \multirow[t]{4}{*}{2012} & Federal & 12 & 695 & 683 & $12 \div 689 \times 100$ & 1.7 \\
\hline & State & 67 & 2098 & 2018 & $67 \div 2058 \times 100$ & 3.3 \\
\hline & Local & - & 644 & & - & - \\
\hline & Private & - & - & & - & - \\
\hline
\end{tabular}

cept for Work Autonomy (p > 0.05).

\section{Discussion}

Most of the respondents (64.9\%) were between ages 41 - 60 years, with mean age of $40.9 \pm 6.4$. This shows the aging workforce in nursing as majority of the respondents will be retiring within the next decade. The study, in line with vacancy situation in South Africa [18] [21] revealed that majority of the nursing leadership positions in Lagos State is vacant and this is as a result of their professional qualification. This gave room for administrators and medical practitioners at the helms of affairs in decision making regarding nursing. As opposed to Briggs [27], all health institutions studied in Lagos State appears to follow the standard strategies during recruitment but not all perform job analysis before embarking on recruitment exercise as almost all the interviewed Managers do not engage in regular personal budgeting or planning which is a major weakness in ensuring effective and adequate nursing workforce. One respondent stated "we do personnel budgeting yearly, but not regularly we don't actually control this thing our job analysis does not include recruitment”. Approval is always sought after before recruitment. This showed how dependent recruitment exercise is on hospital budget and political dispensations corroborating Gberevbie [28] and the leaders' report of Minnesota Hospitals that budgetary constraint often limit their solutions to recruit and retain valued employees [29].

Not all nurse managers organize orientation after recruitment, which might adversely influence the socialization of a newly employed nurse resulting into poor retention [30]. All Lagos State hospitals have existing re- 
Table 4. Nursing vacancy rate calculation of Health Institutions in Lagos State (2008-2012).

\begin{tabular}{|c|c|c|c|c|c|}
\hline \multicolumn{2}{|c|}{ Year/institution } & \multirow{2}{*}{$\begin{array}{c}\begin{array}{c}\text { Number of vacant } \\
\text { positions (GL } 15-17)\end{array} \\
3\end{array}$} & \multirow{2}{*}{$\begin{array}{c}\text { Total number of posi- } \\
\text { tions (GL } 15-17) \\
3\end{array}$} & \multirow{2}{*}{$\begin{array}{l}\text { Calculation of vacancy rates (no of vacant } \\
\text { positions } \div \text { total no of positions } \times 100 \\
\qquad 3 \div 3 \times 100\end{array}$} & \multirow{2}{*}{$\begin{array}{r}\text { Vacancy } \\
\text { rates }(\%) \\
100\end{array}$} \\
\hline 2008 & Federal & & & & \\
\hline & State & 2 & 3 & $2 \div 3 \times 100$ & 66.7 \\
\hline & Local & 3 & 3 & - & 100 \\
\hline & Private & - & - & - & - \\
\hline \multirow[t]{4}{*}{2009} & Federal & 3 & 3 & $3 \div 3 \times 100$ & 100 \\
\hline & State & 3 & 3 & $3 \div 3 \times 100$ & 100 \\
\hline & Local & 3 & 3 & $3 \div 3 \times 100$ & 100 \\
\hline & Private & - & - & - & - \\
\hline \multirow[t]{4}{*}{2010} & Federal & 3 & 3 & $3 \div 3 \times 100$ & 100 \\
\hline & State & 3 & 3 & $3 \div 3 \times 100$ & 100 \\
\hline & Local & 3 & 3 & $3 \div 3 \times 100$ & 100 \\
\hline & Private & - & - & - & - \\
\hline \multirow[t]{4}{*}{2011} & Federal & 3 & 3 & $3 \div 3 \times 100$ & 100 \\
\hline & State & 3 & 3 & $3 \div 3 \times 100$ & 100 \\
\hline & Local & 3 & 3 & $3 \div 3 \times 100$ & 100 \\
\hline & Private & - & - & - & - \\
\hline \multirow[t]{4}{*}{2012} & Federal & 3 & 3 & $3 \div 3 \times 100$ & 100 \\
\hline & State & 2 & 3 & $2 \div 3 \times 100$ & 66.7 \\
\hline & Local & 3 & 3 & $3 \div 3 \times 100$ & 100 \\
\hline & Private & - & - & - & - \\
\hline
\end{tabular}

cruitment policies and majority have retention policies. However, it appears these policies were not usually utilized to the letter. Capacity building for nurses appears to be the priority of all health institutions in Lagos State towards retention as earlier reported about Lagos State Civil service [28]. An interviewee stated "we spend millions of naira every year on training all categories of nurses religiously." Findings revealed that all the three Government parastatal engage in replacement of retired or exited nurses rather than recruiting nurses or increasing retaining efforts. This probably is due to the cost associated with turnover [23].

The study suggests understaffing exists in Lagos State hospitals as reported all over the world as findings from this study revealed that nurses perceived understaffing as existing in their hospitals and some have once committed an omission in the line of duty as a result of workload. This supports the findings from researches conducted in 2007 by the Agency for Healthcare Research and Quality (AHRQ) where shortage of registered nurses, in combination with an increased workload found to pose a potential threat to the quality of care. [11]-[14].

However, the study revealed that not all Managers perceived nurses workload as heavy. One respondent stated "... workload here is normal because some of our nurses still have time to talk and chat...and also have time to attend church programmes every Wednesdays...I pay them and I know how their workload is like".

Despite the fact that in Lagos State, Nigeria, there was a gradual decrease in the number of nurses that graduated from Schools of nursing from 153 in 2009 to 39 in 2011 [10], both the nurse and nurse managers disagreed that limited numbers of nursing schools influences recruitment, supporting this was a statement by a respondent that "We get hundreds of application letters anytime we want to recruit nurses... we need to set standards so as to eliminate...since we cannot recruit everybody...”. This implies that in Lagos State, unemployment coexist with 
understaffing, supporting other reports [1] [31] [32] that insufficiencies often coexist with unemployment in some developing countries.

Hospital's reputation, Salary and allowances, and sense of job security influences the acceptance of employment of nurses in Lagos State, this corroborates the ANA [2006] that facilities reputation is a factor influencing if a registered nurse will accept a job. Findings from the study is suggestive that flexible work, schedule Child care facilities are not strong factors that influences recruitment as opposed to the statement of American Association of Nurses.

The study revealed a wide gap between the efforts of employers towards ensuring retention and what nurses perceived is being done towards retention.

The best factor that influences the nurses to keep working in their hospitals according to this study was increment in salary and allowance as it ranked first among other factors. This finding clearly corroborates the finding by Prescott and Bowen that salary and benefits are leading factors influencing nurses to stay in a workplace and also the supply and demand curves of labour market where when the wages increase (P axis), more people are willing to be employed (Q axis) [33]. Findings from the study revealed that sense of job security, Opportunities for career development, good working environment and opportunities for training and workshops were major factors influencing recruitment and retention. This finding corroborates Mion that there is no single key retention strategy but a multifaceted approach is necessary to create milieu and an environment that retains nurses [34]. As reported by Sourdif [35], job satisfaction was the most consistent predictor of nurses' intentions to remain employed, most of the nurses in these health institutions were not satisfied with their job and so many are not sure of remaining in their hospitals in the next 5 years.

Findings from the study revealed that a turnover rate of nurses in the State Health Institution is higher than the Federal Heath Institution in Lagos State in year 2008 to 2012. Hospital reputation and remuneration accounted for the difference as one of the respondents interviewed stated “....if you get to Canada today for a job and you mentioned the name of this institution, you are sure to be recognized.” Also, the salary scale used at the Federal level is more robust than that of the State level in Lagos State. Interestingly the turnover rate of the private hospital studied in the study is not high as the Government owned hospitals. This suggests that the private hospital studied had in place better retention strategies than Government owned hospital such as good working condition and work autonomy. A private nurse manager stated “...I determine the number of nurses we need to recruit in this hospital per time".

Statistical significant association was found between age and recruitment and retention of nurses. This indicates that retention efforts should focus on nurses within the age bracket $20-30$ years and $51-60$, as young nurses tend to leave their job for a better one and experienced nurses plan to leave as a result of retirement.

Duration of qualification post RN was found to be significantly associated with retention agreeing with the study of Oyeleye et al. [14] where significant relationships was found among turnover intentions, total years of nursing experience, and RN education levels. Additional professional qualification in nursing is usually not equivalent to promotion or increase in pay in the clinical setting, except for rising above the bar of Grade level 14 , it was therefore not surprising that there is no statistically significant association between highest professional qualification of respondents and retention. While hospital's reputation and monetary incentives influences retention of nurses, Work autonomy does not. Nurses' feeling of job security in respect to the reputation of their hospital and the buoyancy of their salary seems to influence their retention than work autonomy.

\section{Conclusions}

Nursing workforce is essential to quality health care. The strategies for recruitment and retention of nurses in Lagos State were explored to explain the dwindling work force in nursing. Although the factors influencing recruitment and retention of nurses are multifaceted and vary from one health organizations to the other, the strategy for recruitment compare to what to obtain in other places however retentions was largely dependent on financial factors. This may be a product of poor and uneven circulation of resources in Nigeria that predispose to the search of a greener pasture.

The knowledge of these influencing factors provides nurse managers with evidence-based information from which they can develop policies and engage best practice management, which is expected to enhance positive patient' health outcomes and nurses' well-being, hence improve recruitment and retention efforts.

The concern about the well being and retention of nurses is relatively new, hence, the major strength of this 
study is that it is one of the few study in Lagos State on recruitment and retention of nurses.

\section{Limitation}

Nurses working outside of the clinical settings were not included in the study.

\section{References}

[1] World Health Organization. The World Health Report 2006-Working Together for Health. WHO, Geneva, 2006. Assessed May 2013.

[2] Anand, S. and Barnighausen, T. (2004) Human Resources and Health Outcomes: Cross-Country Econometric Study. The Lancet, 264, 1603-1609. http://dx.doi.org/10.1016/S0140-6736(04)17313-3

[3] World Health Organization. Workload Indicators of Staffing Need (WISN): User's Manual. Geneva, 2010. http://www.who.int/hrh/resources/wisn user manual/en/

[4] Awofeso, N. (2008) Managing Brain Drain and Brain Waste of Health Workers in Nigeria. WHO. http://www.who.int/bulletin/bulletin board/82/stilwell1/en/

[5] Adesanya, T. (2005) Nigerian Doctors in North America. www.journalism.ryerson.ca/online/hubbub/hogs/tadesanya3.htm

[6] Nnamuchi, O. (2007) The Right to Health in Nigeria. Law School, University of Aberdeen. Draft Report. http://www.abdn.ac.uk/law/hhr.shtml

[7] Chankova, S., Nguyen, H., Chipanta, D., Kombe, G., Onoja, A. and Ogungbemi, K. (2007) Catalyzing Human Resources Mobilization: A Look at the Situation in Nigeria. Abt Associates Inc. May 30, 2007 Global Health Council Annual Conference, Washington DC.

[8] Gordon, S. (2005) Nursing against the Odds: How Health Care Cost Cutting, Media Stereotypes, and Medical Hubris Undermine Nurses and Patient Care. http://www.nursingadvocacy.ord/media/books/nursing_odds.html

[9] Bureau of Labor Statistics. Occupational Outlook Handbook, 2010-2011 Edition. http://www.bls.gov/oco/ocos083.htm

[10] Nursing and Midwifery Council of Nigeria, Statistics of Nurses, 2012.

[11] Wilson, C. (2006) Why Stay in Nursing? Nursing Management, 12, 31.

[12] Aiken, L.H., Clarke, S.P., Sloane, D.M., et al. (2002) Hospital Nurse Staffing and Patient Mortality, Nurse Burnout, and Job Dissatisfaction. JAMA, 288, 1987-1993. http://dx.doi.org/10.1001/jama.288.16.1987

[13] Vahey, D.C., Aiken, L.H., Sloane, D.M., et al. (2004) Nurse Burnout and Patient Satisfaction. Medical Care, 42.

[14] Oyeleye, O., Hanson, P., O’Connor, N. and Dunn. D. (2013) Relationship of Work Incivility, Stress, and Burnout on Nurses’ Turnover Intentions and Psychological Empowerment. Journal of Nursing Administration, 43, 536-542. http://dx.doi.org/10.1097/NNA.0b013e3182a3e8c9

[15] International Council of Nurses. Health Human Resources Planning. Geneva, 2008. http://www.ichrn.com/publications/factsheets/Health-Human-Resources-Plan_EN.pdf

[16] Lai, H., Peng, T. and Chang, F. (2006) Factors Associated with Career Decision in Taiwanese Nursing Students in Three Types of Programs. Journal of Nursing Education, 43, 581-588.

[17] Zurmehly, J. (2008) The Relationship of Educational Preparation, Autonomy, and Critical Thinking to Nursing Job Satisfaction. Journal of Continuing Education in Nursing, 39, 453-460.

[18] Oosthuizen, M.J. (2005) An Analysis of the Factors Contributing to the Emigration of South African Nurses. Unpublished D Litt et Phil Thesis, Department of Health Studies, University of South Africa.

[19] Ellenbecker, C.H., Samia, L., Cushman, M.J. and Porell, F.W. (2007) Employer Retention Strategies and Their Effect on Nurses' Job Satisfaction and Intent to Stay. Home Health Care Services Quarterly, 26, 43-58. http://dx.doi.org/10.1300/J027v26n01_04

[20] Gberevbie, D.E. (2010) Strategies for Employee Recruitment, Retention and Performance: Dimension of the Federal Civil Service of Nigeria. African Journal of Business Management, 4, 1447-1456.

[21] The American Nurses Association. Appropriate Staffing, 2006. http://www.nursingworld.org/staffing

[22] Health Systems Trust (HST) Percentage of Professional Nurse Posts Vacant. www.hst.org.za/healthstats/140/data

[23] Jones, C.B. (2005) The Costs of Nurse Turnover. Journal of Nursing Administration, 35, 41-49. http://dx.doi.org/10.1097/00005110-200501000-00014

[24] Lagos State Bureau of Statistics 2005.

[25] Statistical Package for Social Studies. Version 17.0, SPSS Inc., Illinois, Chicago. 
[26] Marshall, C. and Rossman, G.B. (1995) Designing Qualitative Research. 2nd Edition, Sage, Thousand Oaks.

[27] Briggs, B.R. (2007) Problems of Recruitment in Civil Service: Case of the Nigerian Civil Service. African Journal of Business Management, 1, 142-153.

[28] Gberevbie, D.E. (2009) Personnel Recruitment and Retention Strategies in Lagos State Civil Service of Nigeria. African Research Review, 3, 226-243. http://dx.doi.org/10.4314/afrrev.v3i3.47526

[29] Minnesota Hospital Association. Personal Communication. 13 April 2007.

[30] Marcum, E.H. and West, R.D. (2004) Structured Orientation for New Graduates: A Retention Strategy. Journal for Nurses in Staff Development, 20, 118-124. http://dx.doi.org/10.1097/00124645-200405000-00003

[31] Organization for Economic Cooperation and Development. OECD. The International Mobility of Health Professionals; An Evaluation and Analysis Based on the Case of South Africa, 2004.

[32] Volquartz, J. (2005) The Brain Drain. Guardian. 11 March 2005.

[33] Antonazzo, E., Scott, A., Skatun, D. and Elliot, R. (2003) The Labour Market for Nursing: A Review of the Labour Supply Literature. Health Economics, 12, 465-478. http://dx.doi.org/10.1002/hec.737

[34] Mion, L.C., Hazel, C., Cap, M., Fusilero, J., Podmore, M.L. and Szweda, C. (2006) Retaining and Recruiting Mature Experienced Nurses: A Multicomponent Organizational Strategy. Journal of Nursing Administration, 36, 148-154. http://dx.doi.org/10.1097/00005110-200603000-00009

[35] Sourdif, J. (2004) Predictors of Nurses' Intent to Stay at Work in a University Health Center. Nursing and Health Sciences, 6, 59-68. http://dx.doi.org/10.1111/j.1442-2018.2003.00174.x 
Scientific Research Publishing (SCIRP) is one of the largest Open Access journal publishers. It is currently publishing more than 200 open access, online, peer-reviewed journals covering a wide range of academic disciplines. SCIRP serves the worldwide academic communities and contributes to the progress and application of science with its publication.

Other selected journals from SCIRP are listed as below. Submit your manuscript to us via either submit@scirp.org or Online Submission Portal.
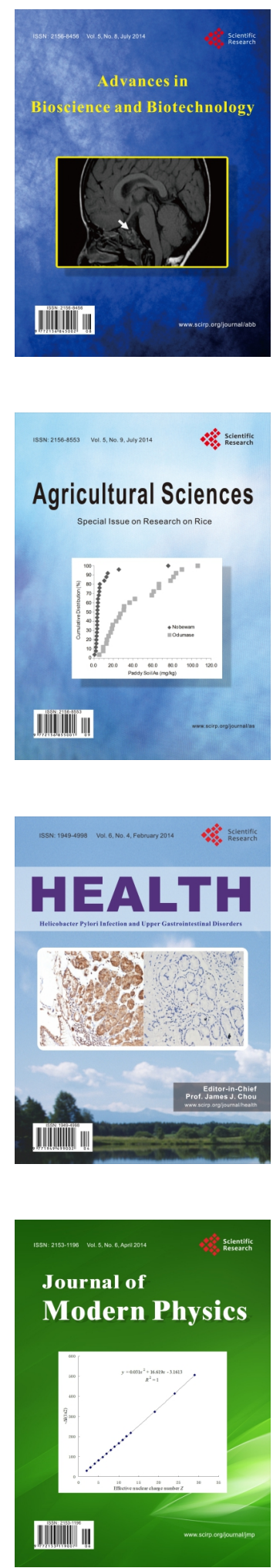
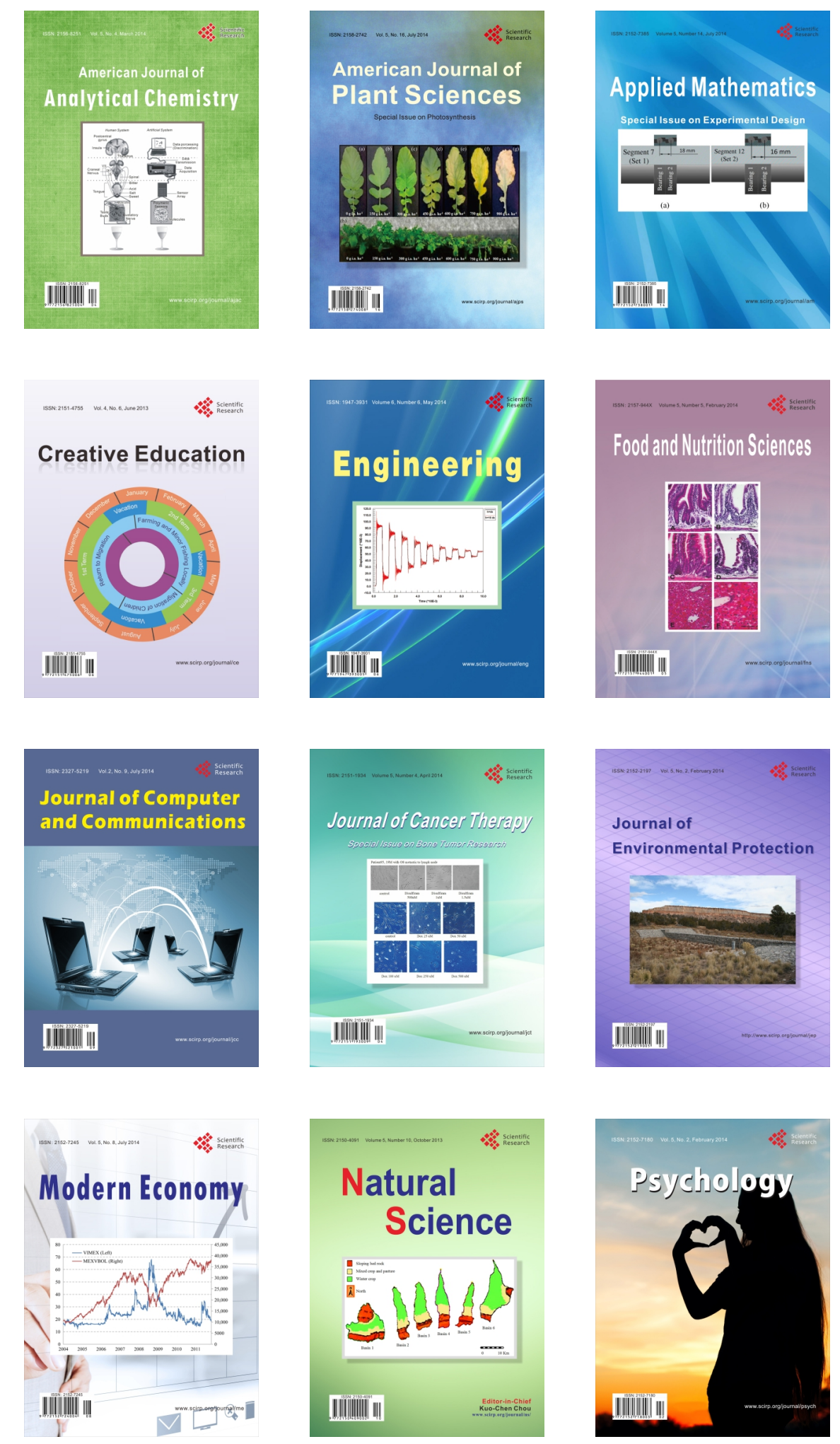